\title{
Lecturer Identities and Perceptions of CPD for Supporting Learning and Teaching in FE and HE in the UK
}

\author{
Charles Buckley \\ University of Liverpool
}

\author{
Gary Husband \\ University of Stirling
}

\begin{abstract}
This paper draws together the findings of two separate studies that were focused on the professional learning of lecturers working in the post compulsory education sector. The studies were conducted independently in separate locations and institutions in the United Kingdom and focused in different sectors of post compulsory education (further and higher). Each study aimed to discover the ongoing professional learning needs of lecturers some years after initial training had been completed. Through conducting semi structured interviews, each researcher gained a situational understanding from the perspective of the respondent lecturers through a lens of their experience and agency. This paper acts an extending study as the researchers bring together their independent results and findings in a further analysis. Focusing on understanding the similarities and differences in experiences, the paper reports several additional findings based on this cross analysis. Further to the pedagogical developments and support for undertaking teaching practice, this research reports that in both communities of further and higher education lecturers, their initial teaching qualifications and related experiences had a more profound and longitudinal impact on their professional identity and practices than they had previously considered. Organisationally, these finding prove to be interesting as it demonstrates that initial training and induction support networks and courses of study, have a longer lasting impact on individuals and consequently, the cultural and social aspects of associated organisations. By looking at the both combined studies, it was possible to broaden the sample size and ascertain whether observed phenomenon were present in a cross sectoral capacity.
\end{abstract}

Keywords: Professional Education; Initial Teacher Education; Teaching and Learning; Higher Education; Lecturer Identity 


\section{Introduction}

Post compulsory education in both further and higher education settings in the United Kingdom (UK) has, in recent years, seen many significant changes. FE colleges have been undergoing mergers to regionalise provision and the blurring of boundaries between schools and colleges, and colleges and universities in provision and curriculum has started to significantly change the direction and scope of post compulsory education, a phenomenon noted by Gallacher (2006) and still very much a policy focus. In universities the 2012 definitional change in the Standard Occupational Classification (SOC) used by the UK's official Higher Education Statistics Agency (HESA) highlighted the changes of the roles carried out by academic and nonacademic staff and the emergence of higher education professionals with related measurable quality standards as a focus of ongoing development. This is characteristic of the expanding perception of the role of HEI's whereby core higher education professionals can be involved in traditional activities of teaching and research with a more recent additional focus on enterprise (Baltaru, 2019). In addition, higher education institutes have been changing from the traditional bureaucratic archetype towards what has been described as a more managerialist modus operandi (Bruckmann and Carvalho, 2018)

The importance, scope and requirements of teacher education courses for lecturers working in post compulsory education have in recent years, also come under considerable scrutiny. As the key performance indicator driven quality tests of compulsory education have been applied to further and higher education institutions, a contentious gradual move towards a market-led model of students as customers and institutions as suppliers has emerged (Feigenbaum \& Iqani, 2013; Williamson, 2011). The introduction of the Teaching Excellence Framework is the most recent iteration (Canning, 2017) and addition to the suite of analytical measures applied to education with the purpose of trying to understand the Quality (capital Q is purposeful in this instance) profiles of institutions. This shift in expectations and the requirements of the colleges and universities within the post compulsory education sector has led to the initiation of changes to the modus operandi of many institutions, the creation of new organisations and the convergence of much practice (Griggs, 2012).

Early career academics in universities and new teachers in FE find themselves in vulnerable positions whereby the expectations of the professional role they have been employed to do become reality, and a steep learning curve is undertaken to begin to accomplish the various aspects of the role. It would be a mistake to consider these developing roles in both sectors to be purely teaching focused. Early career researchers in universities have their research development, grant capture (often as a primary focus), faculty community engagement, administration duties and network and conference responsibilities to balance with their teaching duties (Gale, 2011). FE lecturers new to their role will face similar pressures in relation to administrative duties, a comparatively heavy teaching load and organisational familiarisation. Indeed, the pressure on teaching professionals in both FE and HE does not seemingly disappear with career progression but mutates and evolves along with career stage.

International Journal of Management and Applied Research, 2020, Vol. 7, No. 4 
There is then a need to align professional learning aims specifically with career stage and the contextual nuances of individual organisations (in addition to leadership and mentoring roles). However, drawing together the multiple skills and diverse aspects of the role of the individual to form the well-rounded academic (as argued by Boyer, 1990 and evidenced with the four-demain framework) is an essential aspect of ongoing and continuous professional learning.

\section{Literature Review}

\subsection{Impact of strategic changes in FE and HE}

Since the early 1990s, the further and higher education sectors have seen a consistent updating of policy which has materially changed how both sectors operate and relate to one another. Perhaps one the most significant pieces of policy introduced in the last thirty years was the Further and Higher Education Act 1992. The act materially changed both sectors by elevating polytechnic institutions to university status and incorporating colleges allowing them to operate independently from education authorities. The Teaching Excellence Framework (Department of Education, 2017), when it was rolled out nationally, was designed as the most recent iteration of a model designed to assess the quality of teaching and learning within universities across the UK. Using various data sets (such as continuation rates, student satisfaction surveys, employment rates and pass marks) gold, silver or bronze status is awarded to participating organisations reflecting in a three tier grading scheme the perceived quality of tuition.

Interestingly, and as highlighted by Ashwin (2017), none of the measured criteria actually directly asses or measure teaching practice, more the potential impacts or benefits of high quality teaching, that is to say good national student survey results, exam results, employability and retention figures. In contrast to this (partially at least) colleges are subject to inspection regimes by devolved national quality audit organisations (Education Scotland and Estyn in Wales as examples). These organisations carry out inspections of educational establishments from nursery provision, to compulsory education through to colleges of further education. Many of the same data sets are inspected and incorporated (such as retention, employability and exam results) in college inspections with the addition of teaching observations, student interviews and staff focus group or one to one discussions. The metrics themselves are of course subtly different but as Canning (2017, p. 328) highlights: "by employing the language of 'teaching excellence' we become constricted by the quality regimes which reward and constrain our practice and dehumanise our students". This in itself creates something of a vacuum in relation to the perceived needs of educators in their own learning as pedagogues and what the system requires in order for the workforce to meets its imposed metric. The work here aims to unpick where these two sets of requirements overlap and how the learning needs of educators can be met to the satisfaction of both teacher and FE and HE systems.

Both of the studies detailed in this paper were undertaken to try and develop an understanding of what lecturers in both sectors of post compulsory education felt their learning needs were, what it was they felt they needed to do to or learn in order to

International Journal of Management and Applied Research, 2020, Vol. 7, No. 4 
teach their subject specialism more effectively. This contrasts with understanding what the sector or organisation believes are the professional learning needs. It is not to say that there is no correlation, but to emphasise that there could be significant difference in focus as it is possible that the teaching staff will be focusing on student needs and in contrast, organisations on improving metrics of assessment and inspection and managing the balance between research and teaching outputs of academics (Graham, 2015). The massification of HE (Giannakis and Bullivant, 2015) is now akin to the systems and processes that have become more evident in FE over the last twenty years (O'Leary, 2013).

\subsection{Teaching in Further and Higher Education}

Further education lecturers do not normally carry out or have as a part of their contract, research related activities (Husband and Jeffrey 2016). There has recently been a surge in interest in practitioner research within the FE sector with a broader engagement through the conducting of some large scale projects (see Jeffrey et al. 2015 as an example), however, these kinds of studies are rare and generally partnered with HE organisations for resource and specialist research input.

FE lecturers are teaching focused and can teach up to 26 hours a week in some parts of the UK (regional variance is due to devolved nature of education in the UK). This however, as Feather (2012) highlights is the practical barrier to research engagement and many FE lecturers (especially those engaged in teaching higher education courses) would like the opportunity to conduct and engage with a research remit more readily. The current discourse around the expansion of FE practitioner research in FE is gaining momentum and publications in recent years have seen a sharp increase in FE led momentum, (see Daley, Orr, and Petrie, 2017; 2020 as examples of collections of largely FE based commentators and researchers). Teaching in FE has a broad ranging focus covering many subject areas and disciplines including (as examples) vocational skills training in the trades, the arts and social sciences and is delivered across a broad range of levels (from pre-entry through to postgraduate). Lecturers are frequently individuals engaged in a second (or even third) career (Smith and Hodson, 2010) in teaching, utilising the skills and experience from their earlier career(s) to inform their practice as teachers. Lecturers are generally offered and undertake their initial professional learning to become qualified teachers/lecturers whilst working by completing part time courses with some lecturers (particularly in Scotland) opting for pre-service teacher education, however, graduates of such courses are very much in the minority (Husband, 2015).

In contrast HE lecturers frequently have a more research focused role with as much as $100 \%$ of their time devoted to research activity. This is particularly the case in universities that are grouped as pre 1992 (a title derived from the impact of the Further and Higher Education Act 1992) which converted Polytechnic colleges to Universities) but with a more recent shift to a split teaching and research contract across all universities. However, there are many lecturers that retain a greater teaching focus through maintaining teaching and scholarship contracts which lack the requirement to produce empirical research but do encourage academic engagement. Although there are some teaching focused lecturers in $\mathrm{HE}$, the requirement to engage in research is far

International Journal of Management and Applied Research, 2020, Vol. 7, No. 4 
more common and as such can be considered as a main difference between FE and HE lecturer's roles. The teaching role of HE lecturers can also be very diverse, and as the sector covers many subjects, the remit and skills of lecturers in the sector are equally very variable. However, HE lecturers (who are also engaged in research) naturally teach fewer hours per week than their colleagues in FE and are more likely to foster a professional identity that is not primarily teaching focused but interdisciplinary and dynamic dependent on career stage and focus (Clark, Hyde and Drennan, 2013). Many lecturers in HE have a research teaching and supervision remit that is closely linked to their practice as researchers. The supervision of post graduate research students (research masters and PhDs as examples) is almost entirely unique to universities and as such is a significant difference in the practice of the two groups. However, as Husband and Jeffrey (2016) discuss, any perceived dichotomy of lower level and higher level courses being provided by $\mathrm{FE}$ and $\mathrm{HE}$ respectively is entirely false as many FE lecturers teach degree level courses and equally, many HE lecturers teach pre undergraduate provision (such as access courses).

Lecturers in both HE and FE are providers of a diverse curriculum utilising an equally broad range of teaching methods. Both sets of professionals are engaged in working with a very wide ranging demographic of students and many lecturers in both sectors, have a pastoral remit that goes beyond the requirements of teaching. As Parry (2009) highlights, colleges and universities collaborate and compete under complex, uncertain and often dependent conditions. These relationships and shared practices mean there are often several significant similarities in teaching methods and the roles of lecturers in both FE and HE. It is these conditions that make a combined comparison of studies such as this a useful and interesting addition to the literature.

\subsection{Complexities of funding}

Whilst there are many clear similarities in teaching practice and the roles of lecturers in both FE and HE, there are also several fundamental differences. Further education is structured and funded very differently across the devolved locales of the United Kingdom. This places a particular pressure on the sector as issues related to funding, governance, curriculum, management, policy and demographics are compounded by an almost constant churn in policy, a phenomenon prevalent in all devolved sectors of the UK (Hanley and Orr, 2019). Higher Education programmes are differently funded and form an equally complex policy web. Scottish universities are able to provide tuition fee free undergraduate degrees to residents of Scotland, where the remainder of the UK sectors charge fees of over $£ 9000$ per academic year. Increasingly, universities have had to commercialise to stabilise income streams and place a greater focus on research grant capture to subsidise the salaries of those with both research and teaching remits. The funding landscape across the UK is incredibly complex and outside the scope of this paper, however, it is important to note as the pressures it applies to those working and teaching within these sectors is apparent and real.

\subsection{Dual identity of lecturers and professional development for teaching}

In FE the shift in policy in recent years can be characterised as one of dual professionalism with lecturers being expected continuously to extend and update both

International Journal of Management and Applied Research, 2020, Vol. 7, No. 4 
their occupational and their pedagogical expertise, including through undertaking a PGCert (FE) or as featured here TQFE. FE lecturers are expected to maintain the skills, good standing, and expertise of their industry or academic specialty in order to ensure they are delivering the highest quality training to individuals accessing provision (Köpsén, 2014). However, the sector promotes the use of professional standards which lay out the requirements and expectations beholden on lecturers to build and maintain their skills in teaching and learning practice (see examples Morrison, 2012). This dual professionalism is often a new concept when individuals enter into a career in teaching in FE. People often come directly from careers in industry where their professional focus was on one area of practice and skills development (Feather, 2012a).

In higher education there has been an emphasis on professionalising teaching. Given the impetus to professionalise teaching in higher education, (for example, through the UK Advanced HE drive to encourage university teachers to seek accreditation at Associate Fellowship, Fellowship, Senior Fellowship and Principal Fellowship). Increasingly, CPD courses, processes and events in UK HEIs are mapped against the UKPSF (HEA, 2015) which is therefore arguably asserting considerable influence in the scope and development of CPD.

Many institutions have developed selection criteria or internal promotion tracks which explicitly require staff to discuss and evidence their teaching- and learning-related impact. The sector has built on 20 years of experiences from organisations like the Staff and Educational Development Association (SEDA), the Higher Education Research and Development Society of Australasia (HERDSA) and the antecedent organisation of the Higher Education Academy (HEA), the Institute for Learning and Teaching in Higher Education (ILTHE), the sector-owned UK Professional Standards framework (HEA, 2015), managed and led by the HEA, has been established to recognise and benchmark professional expertise in the area, from relative novices through to the most senior leaders in universities. This shift in higher education has meant that there has been a significant orientation towards teaching and learning to a point where commitment to engaging students in learning has become everybody's business, and this has been recognised by national and international moves towards professionalising higher education (Sambell, Brown and Graham, 2017). The process of learning to teach, and the associated field of professional academic development for teaching has become absolutely central to higher education (Lelbowitz, Bozalek and Kahn, 2017). There has been a growing emphasis on innovative practice e.g. (Flavin, 2017; Peris-Ortiz et al., 2017; Reidsema et al., 2017). This interest has also been accompanied by studies which examine the influence of CPD and teaching excellence awards on individuals and how this affects their professional development (Kneale et al. , 2016; Smith, et al., 2017; Huggett, et al., 2012).

\section{Methods}

\subsection{HE study}

This investigation explored the attitudes and experiences of colleagues involved in a Postgraduate Certificate in Higher Education across six universities in Wales. The

International Journal of Management and Applied Research, 2020, Vol. 7, No. 4 
study focused on the perceptions of lectures of the continuing professional development training they received through the Post Graduate Certificate of Education, Higher Education (PGCEHE), how they felt this affected their conceptions and approaches to learning and teaching as well as any impact on their professional identity in university. Postal self-completion questionnaires ( $\mathrm{n}=38$ responses) were used to gather perceptions about perceived value of the course. A mix of pre-coded Likert scaled and open-ended questions were used to gather information about the extent to which they felt the PGCertHE might benefit their students; be valued by colleagues and the institution; change their conceptions of teaching and develop them as an academic practitioner. Follow-up individual interviews were used with 4 PGCertHE course directors and focus group interviews with 33 lecturers involved at various stages of their award. Three pre-92 and three post '92 institutions were involved. The cross-sectional sample involved colleagues at one of three different stages: 1) Just embarking/embarked on the scheme 'new starter'; 2) about to complete/ recently finished ('completer') and 3) completed at least two years ago ('completed'). Interviews with lecturers were semi-structured and conversations were focused on the key issues relating to their perceptions of the awards. Data from the focus group interviews was recorded and transcribed and then analysed, together with questionnaire data using thematic analysis as described by Braun and Clarke (2006).

\subsection{FE study}

The researcher in this study used semi-structured interviews (Yin, 2011; Drever, 2003) with individuals working in further education colleges who were practising as lecturers. The researcher arranged interviews with ten respondents, ten from a multi campus merged FE college in Wales, and ten from a multi campus merged FE college in Scotland. The aim was to conduct continuous data analysis concurrent with ongoing interviews (Cirgin Ellett and Beausang, 2002). This approach allowed the researcher to monitor and explore emerging themes as the interview schedule progressed and continue until the emerging themes were fully developed (Fossey et al., 2002). The interviews in the college in Wales were conducted over two days to accommodate the researcher and respondents and allow for emersion within the Welsh college community. The interviews in Scotland were conducted over a ten week period with three follow up interviews conducted in September and December. The main focus of the semi-structured interviews was the perceived efficacy of training that had been undertaken, and the impact that this had had on continued engagement with professional learning opportunities. A further focus on the ongoing influence on practice emerged as the interviews progressed. The specific results of this study have been published extensively elsewhere (Husband, 2015; 2016; 2018 and 2020).

\section{Results}

Results from both studies indicated that there are a number of issues which are equally important across the sectors such as with lecturers acknowledging the importance of $\mathrm{CPD}$, on-going training and expressing the desire to engage with relevant courses in learning and teaching; which in turn led to a sense of confidence and credibility. In addition, both studies provided a strong indication that staff appreciated the practical

International Journal of Management and Applied Research, 2020, Vol. 7, No. 4 
examples of ways they could improve their teaching and ability to be reflective practitioners. The findings also suggested that tutors across the sectors had differing expectations about the type of CPD they thought relevant and their perceptions of the ways in which their respective courses and awards had impacted on their professional identity.

\subsection{Main findings of HE based study}

The questionnaire and interview data from all sections of the respondents indicated that, overall, they were positive about the award feeling that it was of professional benefit to them and was recognised by their institutions. Many colleagues thought that being involved in taking the award had changed their conceptions of teaching and learning and developed them as an academic practitioner. There were no real notable differences between the three categories of respondents from the cross-sectional sample, although those who had completed the award more than two years ago were a little more sceptical about how important the award was valued by colleagues in their institution compared with new starters and those just completing.

\subsection{Main findings of FE based study}

The main themes which emerged from the FE study were that tutors were mostly positive about the modes of training they had received and felt that these were effective with practical and vocational aspects of the course being the most valued. Lecturers wanted more training on classroom management and delivery techniques. They also felt that lecturer training has a positive impact on the student experience. In relation to their CPD, the research indicated that lecturers trained in Teacher Qualification in Further Education (TQFE) (Scottish teaching qualification) are more likely to undertake CPD in subject specialism than in pedagogic development; there is frequent confusion as to what constitutes CPD and there are some problems associated with accessing relevant and high quality CPD. In addition, there was a feeling that training has an effect on learning and engagement with CPD but that this is not always positive.

Thematic analysis of data from across the two sectors generated a number of recurrent themes:

\section{Worthwhile and recognised but not enough practical}

Within the FE context, whilst colleagues were appreciative of the relevance of the training they received, there were a number of caveats mostly relating to having the space within heavy workloads to effectively engage with the course. For colleagues in $\mathrm{FE}$, the thematic analysis of the data showed that many of the respondents felt that their training had been effective in preparing them to teach and that the model they undertook prepared them well for their role. Practising for over 5 years as a qualified lecturer and working in a promoted position in Scotland, Isla (all names are pseudonyms) felt that the training she undertook had been successful but also at the same time challenging:

"Following a four programme of training worked well as there was a gradual increase in the workload, level of work and expectations of each course. It

International Journal of Management and Applied Research, 2020, Vol. 7, No. 4 
became increasingly challenging as work responsibilities increased over time so did the amount of work in the training courses, this was all completed over and above contracted work without any remission."

Bryn, a lecturer practising in Wales had a 35-year long career in public service prior to entering into a second career as a lecturer in FE. Bryn held some reservations initially about undertaking the teacher training for his role and questioned the validity or retraining in his fifties, especially after a career as an instructor. However, Bryn's reflections regarding the general efficacy of his training were very clear as he recalled his feelings towards the experience:

"At first I didn't really see the point but I think I was very lucky with my tutors who were brilliant. I can teach trainees [military] in a gym all day long, no problem, but my Cert Ed taught me how to calm down and teach students in a classroom, it was good for that."

Some of the respondents discussed the levels of work required, the amount of work undertaken alongside teaching loads and the difficulties experienced in managing time and producing work of sufficiently high quality to warrant submission. There was no evident emergent links between the models or types of training undertaken and overall satisfaction.

In similar ways, colleagues in the HE context, for nearly all colleagues at various stages of the award, there was a recognition that the time spent studying for the qualification had been worthwhile and that there were multiple benefits. Each university provides an induction, some at a residential venue outside university, and others in house. Following this, the courses follow an action-based learning model where colleagues work with a mentor in their own discipline. On-going academic development workshops feature and these received particularly positive comments from colleagues. Whilst the majority of colleagues are positive about the value of the course and impact on their conceptions of teaching, the generic nature of the schemes was criticised by a minority who felt that there should be more subject-specific materials to help them support students in their own disciplines. There were often initial tensions with adapting to the new language associated with pedagogical theories and a reluctance to engage with them. However, for the most part, colleagues who progressed through the award ultimately saw real purpose in engaging with theoretical models:

I started off wanting tips and was a bit disappointed because the programme, when we're actually in class is quite theory based but then I think something that's quite clever with this programme is the assignments are much more reflective on your teaching, so that's where you pick up the practical oh this is what the theory means in practice stuff and I think that's quite clever really (Alison, 'Completer working in a post '92 university)

In FE, whilst colleagues were mostly positive about the training they received, the also felt that there needed to be more of an emphasis on vocational and practical aspects of the courses. A common theme began to emerge from the interviews that the vocational aspects of the training courses were commonly regarded as being the most important and influential to practitioners and on their practice. Susan for example stated that:

International Journal of Management and Applied Research, 2020, Vol. 7, No. 4 
"The best bit of the course was the practical training at my placement college. That was really useful because really, you are learning on the job".

In a similar way, William commented:

"TQFE didn't give me the practical application I was looking for. I was told to prepare lesson plans and schemes of work but not shown how to do it. In all the time I have been working and training I have never seen anyone else teach a class, I don't know how other people do it. The training was very generic nothing at all about subject specialisms which made it feel very vague".

There was also, in both sectors, a realisation of the growing importance of having a relevant teaching qualification. In the FE study for example, although many lecturers feel that they struggled to attend high quality and relevant CPD, there was no lack of recognition of the importance of professional learning and constant updating. Many respondents talked about their engagement with further training and lifelong learning as being of importance to them and their practice. In addition, the research suggests that lecturers in FE are aware of the importance of their dual professional status.

In interviews with colleagues in universities, colleagues made reference to the changing landscape in terms of the importance attached to issues such as student retention and accreditation. For example:

I also think culturally across the country, across the UK with the fee structure changing teaching is going to be a much bigger thing, and any school that is ignoring it is going to have a very nasty shock when their student numbers drop Now there are about nine of us who have completed this course and we're really did quite a lot, we formed these little communities, advising all the members what teaching is and etc, etc. And, we've started climbing up the league tables (Alun, 'Completer' pre '92)

For nearly all colleagues in both the $\mathrm{FE}$ and $\mathrm{HE}$ focused studies, there was a recognition that the time spent studying for the qualification had been worthwhile and that there were multiple benefits. Many of the benefits were perceived to be opportunities to link and network with colleagues from other disciplines and share what they perceived to be good practice; the increasing attention nationally to the importance of having such a qualification for career development; encouraging reflective thought and having the ability to be able to critique one's own practice.

\section{Improving teaching and benefitting students}

A second commonly occurring theme evident in both studies was the acceptance amongst respondents that the undertaking of the respective programmes of learning had positive impacts on pedagogic practice and consequently, in their view, the learning experiences of students. Although neither study engaged in interviews with students, this theme was identified by the respondents in both research projects through the lens of their own practice. Specific aspects of practice identified related to the quality of preparation, structuring feedback and a student focused approach to teaching. This clearly had differing connotations in the separate studies and due to the modes of teaching practice, environments and predominant sectoral foci (both level and pedagogically). However, the learning of the respondent lecturers, through

International Journal of Management and Applied Research, 2020, Vol. 7, No. 4 
undertaking the respective (and sector specific) courses, had clearly had fundamental impact on how they thought about teaching and learning.

Eve, a science teacher in FE of over 20 years, placed significant value on the training and identified that she believes it does have an important impact on student learning from a practical and administrative point of view:

"Teacher training definitely, makes a difference as individuals are aware of curriculum, procedures, assessments and role requirements. Experience gained through training and practice has the greatest impact on student learning".

Eve highlighted the importance and significance placed on the competency in practice of lecturers that can potentially be developed through engagement with training. Similarly, Gwenda who teaches art was also positive in her response and provided a useful insight in relation to the perceived performance of her colleagues:

"Training has a big impact on quality, the staff that are not trained stand out from those that are as being less effective".

Similarly from the HE context, support for the development of creative practice with direct impact on students was suggested:

"The course has helped me think creatively when introducing new techniques, students react better, I now have a better understanding of how people learn and assess which techniques are likely to be most effective." (Sandra post '92 completed.)

In $\mathrm{HE}$, the perceived impacts on practice were seen to be more far reaching as it not only had an influence on their pedagogy, but was seen to have a broader influence on other areas of professional life common to many HE academics:

I think it encourages you to critique your own research really and looking it from a pedagogical point-of-view. (Male, 'Starter', pre '92)

Importantly, this points to an engagement beyond the practical and performative aspects of simply undertaking training and to a more fundamental and far reaching change in practices associated with both lecturer's roles in FE and HE. The influence on creativity and practice has extended into influencing a different way of thinking about teaching and learning. The reflections and responses given went beyond the simple recollection of practical implications of day to day practice, and started to critically question and reflect on how their thinking in relation to teaching and learning had been affected.

...it is quite different to how I expected where on the one level turning up I was thinking, this is going to teach me how to teach. It's like it's not, it's teaching you how to think about teaching and learning. It is very different. (Male, 'Starter', pre '92).

However, in commenting on the focus on teaching and learning and the courses undertaken to develop these areas of practice, comments were received from respondents in both the FE and HE studies that pointed towards similar concerns in relation to subject areas. Despite the fact that most FE lecturers were positive about the impact of the training courses on their teaching and subsequent impact on their

International Journal of Management and Applied Research, 2020, Vol. 7, No. 4 
students, some felt that in many respects, their subject specialism and identity as professionals within their fields of expertise were seen to be more important or needed constant and preferential focus.

Although Iwan who has taught Information Technology for 8 years had seen the value of some aspects of his initial teacher education course he highlighted a problem:

What makes a greater difference [to students] is subject specialist knowledge. I have been out of industry for 8 years now, my teaching skills have improved and increased but my specialist knowledge has decreased. There needs to be a much better system to address that".

Similarly in the HE context, when discussing professional identity and teaching and learning, Keith raised a related critique and observation highlighting both institutional and professional differences in foci between $\mathrm{HE}$ and FE:

So, not sure, but in my discipline of pharmacy a doctorate and research output are viewed as far more substantive than a teaching course (Completer, pre '92 university)

Colleagues reported that they felt they had increased credibility, particularly amongst their peers if they had completed the award. For many, it also provided a springboard for future CPD activities and some reported that it had given them the skills to reflect at a deeper level about their broader practice as both teachers and researchers.

\section{Continuing with professional development and learning}

For many of the respondents in both FE and HE, being involved in the awards had also provided a springboard for future CPD activities. There was an overall consensus about the value and importance of being involved in some sort of CPD across the sectors with lecturers acknowledging the importance of training and expressing the desire to engage with relevant courses in learning and teaching. A number of colleagues, especially those from the HE sector, had gained a momentum which they continued with further postgraduate study or making contributions to the award such bas offering to deliver workshops or setting up initiatives relating to learning and teaching in their disciplines. However, whilst colleagues in both FE and HE were generally positive about the value of $\mathrm{CPD}$, there was a more positive response from lecturers in HE

I am now able to take seriously CPD specific to teaching and learning. I used to identify myself with reference to my disciplinary specialisation, now I find myself claiming that I am a practitioner in higher education" (Male Completer post '92)

There seemed to be a very positive shift toward the course providing increased interest in further CPD such as workshops in learning and teaching and further study.

Yes because I have been able to engage in a critical dialogue with colleagues. I have since gone on to MA and professional doctoral programme. I value engagement in research to support my practice. I am a more confident individual as a result of postgraduate study. (Peter, Completer 'Pre '92)

For colleagues who were new to university teaching and those who had moved from other professions, the teaching qualification provided them with insights into the nature of teaching and a willingness to try new ideas with their students. For those who

International Journal of Management and Applied Research, 2020, Vol. 7, No. 4 
had previous teaching experience it either provided them with new ideas they could apply to higher education or reaffirm that their practice was good.

I've come on leaps and bounds as a lecturer in the last couple of years and I think that it can't be down to anything other than this particular course. (Male, Starter pre-92 university).

A number of colleagues made reference to the growing importance of teaching awards nationally and this combined with their interest in pedagogy seemed to influence their desire to continue with future study.

I am now aware of research in this area and the importance of keeping up-to-date. I feel well-read having had to read to complete assignments within the course. The workshops inspired me and I intend to continue going to future workshops. (Alan, Completer, post '92)

In FE, there was a mostly positive but more nuanced response to CPD (often now referred to as career long professional learning CLPL). The data indicated that lecturers undertook and valued CPD more so in subject specialist areas of development irrespective of the model of training that had undertaken. However there was a lesser engagement with pedagogic CPD for lecturers that undertook the part time one-year distance learning model of training (TQFE in Scotland). This model also shows that lecturers that had undertaken a pre-service qualification (secondary school training or pre-service TQFE) and the two-year day release model of training (PG Cert in Wales) engaged equally with pedagogy focussed CPD and subject specialism CPD.

Luke who teaches in Scotland was quick to advocate CPD in subject specific areas: "CPD is vital for lecturers, specifically in their subject areas. Without it the courses are not sustainable unless you employ new staff every year".

Isla who practices in Scotland was also positive about her subject specialist CPD experiences:

"I've done quite a lot of specialist training in my subject area. It's had a really positive impact on my teaching".

John who teaches science in Scotland has mainly focussed his CPD engagement on keeping up to date in his specialist field:

"I think most of my CPD has been on developing my [subject area] expertise. I've done hardly any CPD for teaching. I access most courses externally to the college because of the nature of the training. I think that CPD is really very important. Staying up to date with subjects keeps them alive for you and that means more interesting for your students too. There should be much more time made available for CPD and a much more emphasis on it for lecturers".

This approach by lecturers in placing emphasis on their subject specialist fields was wide spread within the community of TQFE graduates in Scotland. Less evidence emerged in the data of interest in or engagement with pedagogic development CPD or any type of continuing professional enquiry. When asked about CPD for learning and teaching lecturers reported a lack of time, too much work or the pressures of personal

International Journal of Management and Applied Research, 2020, Vol. 7, No. 4 
life as being preventative factors in the investment of effort and resource in exploring and engaging with further courses.

When lecturers that had undertaken other forms of training from TQFE were asked the same questions, a much greater spread of responses was received. Recognition of the development of dual professional values and skills came through clearly. Although many of the same pressures were cited, they were expressed when talking about all types of professional learning and not just development in pedagogic practice.

Dewi who teaches on business and finance courses in Wales had a much greater emphasis on the CPD he had undertaken in pedagogic development:

"My training has really influenced my approach to CPD. I didn't feel much like a finished article after training and knew I wanted and probably needed to learn a lot more about teaching".

During the course of the interviews in the FE sector, there were several instances of respondents expressing their frustration at not being able to access CPD of value or citing time pressures and workload exerted restrictions as causing them difficulty. Furthermore, Not all indications of influence of training on CPD were positive as some respondents felt that their experiences in teacher training had put them off seeking further learning opportunities, especially in pedagogic development.

Despite some reservations in FE, for nearly all the respondents across the sector their engagement with the awards had increased their level of critical reflection, selfconfidence and professional identity.

\section{Confidence and shaping identity}

A further common theme between both studies emerged when the interviews addressed the issues of professional confidence and identity. Despite some differences in the way $\mathrm{FE}$ and $\mathrm{HE}$ colleagues viewed different types of CPD, there was also recognition that it had had an impact on their professional identity and made them a more reflective practitioner. For example:

Mary, an FE lecturer from Scotland said:

"Teacher training definitely taught me to reflect which had a big impact on how I engage with CPD and teaching".

Similarly, Gwenda, who trained and teaches in FE in Wales, discussed how training had changed her learning:

"Training has not changed my approach to CPD but has changed the way I learn.

I am definitely more reflective. I often think about how to do things better and if I need some training I will try and get it”.

There were also positive comments from HE colleagues about the impact of CPD activities on their conceptions of learning and identity:

I am now able to take seriously CPD specific to teaching and learning. I used to identify myself with reference to my disciplinary specialisation, now I find myself claiming that I am a practitioner in higher education"

International Journal of Management and Applied Research, 2020, Vol. 7, No. 4 
A consistent and striking aspect from interviewing colleagues was the impact that studying and/or completing the award had on their confidence. They felt in a better position to be able to answer questions from students, and following student leads in a more student-centred setting:

I'm much more confident in just going with the flow and exploring different avenues and know that I've got the skills to get back to the point eventually, somehow. (Male, 'Completer' Pre- 92)

I'm probably more confident asking questions and going with the flow, I don't feel I have to have a huge structure like I used to of everything but my thinking behind what I do is very different, I think my reasoning of why I do stuff is different I think. (Male, Completer, pre '92)

Nearly all respondents, when asked about whether the course has impacted on their identity were positive about the opportunities it had afforded them to become part of a network and become accepted into university life, both from their interactions with colleagues and students.

I used to identify myself with reference to my disciplinary specialisation, now I find myself claiming that I am a practitioner in higher education" (Paula, Completer post -92)

It has been hugely influential on my thoughts on learning and teaching. Without the award it would have been a long, lonely process. It has given me structure to my introduction to academia. The theories we covered have shaped my teaching. (Anthony, Completer pre '92)

For those with a professional background new to academic life, the award was often viewed as a rite of passage into university and they had reconfigured their view of themselves to one of a university lecturer, influenced by their conceptions of teaching, student learning and by the ways in which their colleagues viewed them.

Yes, I feel it has been suitably altered. Being one of the few in my department to have such an experience I am sometimes regarded as some kind of pedagogic expert. Overall, this is positive though it does sometimes involve being asked to take on extra responsibilities. (David, Completer Pre 92 university)

"I guess I feel it has changed. When I started in my post, I was an audiologist who was trying to teach. Now, completing the award makes me feel like I am an academic who specialises in Audiology." I also feel I can now teach beyond my subject specialism given time to prepare. (Male Completer pre/92)

When asked about professional identity and their perceptions of what this meant to them individually, the majority of respondents in FE were quick to identify themselves as lecturers, teachers or educators. The primary and initial identity was that of teacher with the subject specialist aspect of their professional identity playing a secondary role. One respondent identified herself as an artist educator, this was of interest as she also placed priority on her artistic practice stating that without it she could not possibly teach. This showed an awareness of the links between the identified aspects of dual professionalism as subject specialist and teaching practitioner. This research suggests that lecturers in FE are aware of the importance of their dual professional status and

International Journal of Management and Applied Research, 2020, Vol. 7, No. 4 
also of the criticality of engaging with training and CPD to develop and maintain their skill set in all aspects of their work.

Further to this was the apparent sense of becoming described by the respondents when asked about the point at which they felt they had become a professional lecturer as opposed to identifying with their previous professional identity.

Anwen described her change in professional identity as a slow gradual process: I didn't feel I could call myself a lecturer until I had been teaching a few years I guess, finishing my Cert Ed [teaching award] reinforced this.

Hugh also pointed to a perceived change;

It wasn't until I had completed my CertEd that I really felt I could say, yeah, I'm a lecturer.

Susan had similar thoughts related to the teaching award she completed;

I felt it on the first day, I really felt my identity had shifted and I could honestly say I'm a lecturer

There is an interesting parallel as, although there were some identified differences in the perceptions of impact on teaching practice between respondents in the HE and FE studies, there seems to have been a common impact on identity. The sense of professional change and becoming was evident in both communities and perhaps indicates that the effects of individuals undertaking to complete an award in teaching and learning have a far more reaching impact than of that on pedagogic practice. The sense of becoming was transforming the professional identity and perceived status of individuals which in turn may well also impact of professional communities and organisational culture.

\section{Discussion}

In both FE and HE contexts, nearly all comments about the ways in which the courses were structured were very positive. The research in FE explored perceptions of colleagues receiving training through various models which were vocational and experiential, online and distance learning and blended. The majority of training courses are undertaken by teachers whilst they are fulfilling contracts and managing a timetable of teaching. Some trainees are given remission in teaching obligations to undertake studies, but increasingly this is becoming the exception. FE based teacher training courses in Wales are often delivered in partnership with universities utilising licence agreements to facilitate delivery within organisations using their own FE based staff, this is however not the case in Scotland. In the HE study lecturers follow courses which involve an induction event, sometimes over two-three days followed by attendance at occasional CPD workshops and independent study usually with the support of a mentor. The courses have an emphasis on exploring the relationships between various established pedagogical approaches and theories and teaching in a particular context with an emphasis on mapping against the UKPSF (HEA, 2015). The different contexts invariably shape the perceptions of colleagues across the two sectors, however, in the studies, there were clearly common themes transcending the

International Journal of Management and Applied Research, 2020, Vol. 7, No. 4 
contrasting environments in that CPD was thought to be valuable in influencing practice, developing confidence and shaping identity in positive ways.

The research from these two studies suggests that nationally recognised qualifications are valuable. Although there was criticism of the way in which some of the learning was carried out and the programmes offered, this criticism was more accurately levelled at organisational structuring as opposed to the learning itself. Interestingly, through the analysis of the data in the FE study, the two differing models were shown to illicit different responses from participants in relation to their ongoing CLPL focus. The tightly managed and structurally coherent model seen in the Welsh college encouraged an ongoing engagement with CLPL in pedagogic related practices. This was due to the cultural importance placed by the organisation and teaching community within the college on pedagogy and perceived quality of learning experience. The Scottish college did not follow in this and participants were more keen to discuss their CLPL in reference to their subject specialisms.

Culturally, pedagogic development was not supported centrally as a foundation embedded in college structures but seen as secondary to subject specialisms and an expense. In both settings the respondents made favourable comments about much of the teacher education courses (the aspect provided by the partner universities) and saw the value in the learning. This then indicates that the cultural organisation of the college itself plays a greater role in determining future learning needs than the academic courses alone. The nationally recognised courses were a useful framework upon which to build pedagogic development opportunities for new colleagues, a process, in this instance, more completely embraced by the Welsh college.

The studies highlighted a number of differences in the way that programmes are run and perceived across the two sectors. Theory was seemingly more relevant to respondents in $\mathrm{HE}$ where in $\mathrm{FE}$, it was seen as less important and colleagues wanted to be engaged in work-based practical learning. This came through strongly in the responses where those working in FE repeatedly stated the importance and their emphasis of wanting to learn whilst working. The practical experience of teaching became the training ground for ongoing learning. Colleagues in HE were more focused on the theoretical perspectives offered by the academic aspects of the teacher education programmes and made links directly through to practice (this prevailed even though the different courses are frequently taught at the same academic level). This offers an interesting insight and perhaps should not be a surprise. Although the dichotomy of colleges is being vocational and universities being academic are false, there has to be some recognition of the potential for differing backgrounds of those participants engaging as respondents. Colleges of FE are potentially more likely to employ vocational experts such as mechanics, building trades professionals and care work experts (as broad examples).

The training and development for all of these roles is almost entirely structured around practical skills development. This is not to say that university colleagues are without practical skills, this is not the point being made at all. However it serves to illustrate, the agency, background, history and experiences of individuals is critical in

International Journal of Management and Applied Research, 2020, Vol. 7, No. 4 
engagement with the different types of courses and aspects of those courses currently available. There are potentially several important crossovers to be explored in future work related to the idea that there is perhaps a need for a dually developed and offered course focused on adult learning in pot compulsory education that both HE and FE colleagues could participate in and is recognised in both FE and HE sectors.

\section{Reflections and Recommendations}

Some of the key factors which seem to influence lecturer perceptions of CPD in FE are the time available to engage and a need to provide practical and vocational training which recognises the importance of the dual professional role which characterises most practitioners in the sector. This implies the need for a flexible approach to delivering CPD which can be tailored and adapted by individual staff to accommodate the nuances of their specific disciplines. In addition, there could be closer links between awards and CPD provision in learning and teaching. The provision could be further enhanced by a greater shift to workload recognition and a reorientation in courses to more practical and vocational work-based teacher education. Policy makers within devolved FE sectors should also consider the potential benefits of a reprofessionalisation of the FE sector which could be helped by adopting national policy driven levels of required qualification, much like compulsory education (this is currently the position in Scotland, but seemingly not enforced either nationally or contractually). We recommend a further study that considers ideas such as national registration with a professional body, minimum teaching qualification levels for lecturers but, and vitally, considered through a lens of supportive development and not punitive classification.

In higher education, whilst generic CPD is generally well received and practitioners can relate the theoretical and conceptual models to their own context, there should also be a focus on discipline-based CPD "it is argued that academic development has a greater chance of succeeding if it aims at the working-group level, challenges the discipline values and takes an outsider perspective (Bager-Elsborg, 2018) The shift towards recognising and valuing such teaching awards and good-standing through engagement in various forms of CPD will continue to play a more critical role in promotional frameworks and institutions have a role in celebrating and disseminating internal achievements as colleagues gain teaching fellowships through taught awards.

There is a growing acknowledgement that involvement in continuing professional development for teaching and learning and institutional recognition can have a positive impact on confidence and professional identity leading in turn to a shift in conceptions and approaches to teaching in both FE and HE Teaching programmes are more than just influencing pedagogy, they are concerned with the whole professional person. Having the award makes them feel credible, our research indicates awards impact identity, the recommendation is that they have an important role in shaping practice, enhancing the student experience and shaping the professional identities of teaching staff across both FE and HE.

International Journal of Management and Applied Research, 2020, Vol. 7, No. 4 


\section{Reference}

1. Ashwin, P. (2017), "What is the Teaching Excellence Framework, and will it work?", International Higher Education, Vol. 88, pp.10-11. https://doi.org/10.6017/ihe.2017.88.9683

2. Bager-Elsborg, A. (2018), "How lecturers' understanding of change is embedded in disciplinary practices: a multiple case study", Higher Education, Vol. 76, No. 2, pp.195-212. https://doi.org/10.1007/s10734-017-0195-0

3. Baltaru, R. (2019), "Universities' pursuit of inclusion and its effects on professional staff: the case of the United Kingdom", Higher Education, Vol. 77, No. 40, pp.641-656. https://doi.org/10.1007/s10734-018-0293-7

4. Boyer, E. (1990). Scholarship Reconsidered: Priorities of the Professoriate, Washington: Jossey Bass.

5. Braun, V. and Clarke, V. (2006), "Using thematic analysis in psychology", Qualitative Research in Psychology, Vol. 3, No. 2, pp.77-101. https://doi.org/10.1191/1478088706qp063oa

6. Bruckmann, S. and Carvalho, T. (2018), "Understanding change in higher education: an archetypal approach", Higher Education, Vol. 76, No. 4, pp.629647. https://doi.org/10.1007/s10734-018-0229-2

7. Canning, J. (2017), "The UK Teaching Excellence Framework (TEF) as an illustration of Baudrillard's hyperreality", Discourse: Studies in the Cultural Politics of Education, Vol. 40, No. 3 pp.1-12. https://doi.org/10.1080/01596306.2017.1315054

8. Cirgin Ellett, M. and Beausang, C. (2002), "Introduction to Qualitative Research", Gastroenterology Nursing, Vol. 25, No. 1, pp.10-14.

9. Clark, M.; Hyde, A and Drennan, J. (2013), Professional Identity in Higher Education, New York: Springer.

10. Daley, M.; Orr, K. and Petrie, J. (eds). (2017). The Principal: Power and Professionalism in Further Education, London: Trentham Books.

11. Daley, M.; Orr, K. and Petrie, J. (eds). (2020), Calibans Dance: FE after The Tempest, London: Trentham Books.

12. Department of Education (DoE) (2017), Teaching Excellence and Student Outcomes Framework: lessons learned from Year Two, London: Department of Education.

13. Drever, E. (2003), Using Semi-structured Interviews, 2nd ed., Glasgow: University of Glagow.

14. Feather, D. (2012a), "Do lecturers delivering higher education in further education desire to conduct research?", Research in Post-Compulsory Education, Vol. 17, No. 3, pp.335-347. https://doi.org/10.1080/13596748.2012.700110

15. Feather, D. (2012b), "Oh to be a scholar - an HE in FE perspective", Journal of Further and Higher Education, Vol. 36, No 2, pp.243-261.

International Journal of Management and Applied Research, 2020, Vol. 7, No. 4 
https://doi.org/10.1080/0309877X.2011.614930

16. Feigenbaum, A. and Iqani, M. (2013), "Quality after the cuts? Higher education practitioners' accounts of systemic challenges to teaching quality in times of austerity", Journal of Further and Higher Education, Vol. 39, No. 1, pp.46-66. https://doi.org/10.1080/0309877X.2013.778961

17. Flavin, M. (2017), Disruptive Technology Enhanced Learning: The Use and Misuse of Digital Technologies in Higher Education, London: Springer.

18. Fossey, E.; Harvey, C.; Mcdermott, F. and Davidson, L. (2002), "Understanding and evaluating qualitative research", Australian and New Zealand Journal of Psychiatry, Vol. 36, No. 6, pp.717-732. https://doi.org/10.1046/j.14401614.2002.01100.x

19. Further and Higher Education Act 1992 c. 13. Available from: https://www.legislation.gov.uk/ukpga/1992/13/section/65 [Accessed on 30 September 2020].

20. Gale, H. (2011), "The reluctant academic: Early-career academics in a teachingorientated university", International Journal for Academic Development, Vol. 16, No. 3, pp.215-227. https://doi.org/10.1080/1360144X.2011.596705

21. Gallacher, J. (2006), "Blurring the boundaries or creating diversity? The contribution of the further education colleges to higher education in Scotland", Journal of Further and Higher Education, Vol. 30, No. 1, pp.43-58. https://doi.org/10.1080/03098770500432013

22. Giannakis, M. and Bullivant, N. (2015), "The massification of higher education in the UK: Aspects of service quality", Journal of Further and Higher Education, Vol. 40, No. 5, pp. 630-648. https://doi.org/10.1080/0309877X.2014.1000280

23. Graham, A. (2015), "Academic staff performance and workload in higher education in the UK: The conceptual dichotomy", Journal of Further and Higher Education, Vol. 39, No. 5, pp.665-679. https://doi.org/10.1080/0309877X.2014.971110

24. Griggs, R. (2012), Report of the Review of Further Education Governance in Scotland, Edinburgh: Scottish Government.

25. Hanley, P. and Orr, K. (2019), "The recruitment of VET teachers and the failure of policy in England's further education sector", Journal of Education and Work, Vol. 32, No. 2, pp.103-114. https://doi.org/10.1080/13639080.2019.1617842

26. Higher Education Academy (HEA) (2015), The UK Professional Standards Framework. Available from: https://www.heacademy.ac.uk/professionalrecognition/uk-professional-standards-framework-ukpsf/good-standing [Accessed on 3 April 2015].

27. Huggett, K. N.; Greenberg, R. B.; Rao, D.; Richards, B.; Chauvin, S. W.; Fulton, T. B.; Kalishman, S.; Littlefield, J.; Perkowski, L.; Lynne, R. and Simpson, D. (2012), "The design and utility of institutional teaching awards: a literature review", Medical teacher, Vol. 34, No. 11, pp. 907-919. https://doi.org/10.3109/0142159X.2012.731102

International Journal of Management and Applied Research, 2020, Vol. 7, No. 4 
28. Husband, G. (2015), "The impact of lecturers' initial teacher training on continuing professional development needs for teaching and learning in post-compulsory education", Research in Post-Compulsory Education, Vol. 20, No. 2, pp. 227-244. https://doi.org/10.1080/13596748.2015.1030262

29. Husband, G. (2018), "The professional learning of further education lecturers: effects of initial lecturer education programmes on continuing professional learning in Scotland and Wales", Research in Post-Compulsory Education, Vol. 23, No. 2, pp.159-180. https://doi.org/10.1080/13596748.2018.1444384

30. Husband, G. (2020), "The role of mentors in supporting the professional learning of lecturers in further education colleges in Scotland and Wales", Research in PostCompulsory Education. Vol. 25, No. 1, pp. 42-67. https://doi.org/10.1080/13596748.2020.1720167

31. Husband, G. and Jeffrey, M. (2016), "Advanced and higher vocational education in Scotland: recontextualising the provision of HE in FE", Research in PostCompulsory Education, Vol. 21, No. 1-2, pp.66-72. https://doi.org/10.1080/13596748.2015.1125670

32. Husbands, C. (2016), "Teacher education under pressure: Professional learning in an age of global transformation", International Journal of Continuing Education and Lifelong Learning, Vol. 8, No. 2, pp.20-34.

33. Jeffrey, M.; Kelly, I.; Muneer, T. and Smith, I. (2015), "Evaluation of solar modelling techniques through experiment on a $627 \mathrm{kWp}$ photo-voltaic solar power plant at Edinburgh College-Midlothian Campus, Scotland", Journal of Renewable and Sustainable Energy, Vol. 7, No. 3, p.033128. https://doi.org/10.1063/1.4922450

34. Kneale, P.; Winter, J.; Turner, R.; Spowart, L.; Hughes, J.; McKenna, C. and Muneer, R. (2016), Evaluating Teaching Development in Higher Education. Towards Impact Assessment: Literature Review. York: Higher Education Academy.

35. Köpsén, S. (2014), "How vocational teachers describe their vocational teacher identity", Journal of Vocational Education \& Training, Vol. 66, No. 2, pp.194211. https://doi.org/10.1080/13636820.2014.894554

36. Lelbowitz, B.; Bozalek, V. and Kahn, P. (2017). Theorising learning to teach in higher education, London: Routledge. https://doi.org/10.4324/9781315559605

37. O’Leary, M. (2013), "Surveillance, performativity and normalised practice: the use and impact of graded lesson observations in Further Education colleges", Journal of Further and Higher Education, Vol. 37, No. 5, pp. 694-714. https://doi.org/10.1080/0309877X.2012.684036

38. Parry, G. (2009), "Higher Education, Further Education and the English Experiment", Higher Education Quarterly, Vol. 63, No. 4, pp.322-342. https://doi.org/10.1111/j.1468-2273.2009.00443.x

39. Peris-Ortiz, M.; Gomez, J.; Merigo-Lindahl, J. and Rueda Armengot, C. (2017). Entrepreneurial Universities, Cham: Springer International.

International Journal of Management and Applied Research, 2020, Vol. 7, No. 4 
https://doi.org/10.1007/978-3-319-47949-1

40. Morrison, A. J. (2012). Professional Standards for Lecturers in Scotland's Colleges, Edinburgh: The Scottish Government.

41. Reidsema, C.; Kavanagh, L.; Hadgraft, R. and Smith, N. (2017). The Flipped Classroom, Singapore: Springer Singapore. https://doi.org/10.1007/978-981-103413-8

42. Sambell, K.; Brown, S. and Graham, L. (2017). Professionalism in Practice. Key Directions in Higher Education, Learning, Teaching and Assessment, London: Palgrave MacMillan.

43. Smith, K. and Hodson, E. (2010), "Theorising practice in initial teacher education", Journal of Education for Teaching, Vol. 36, No. 3, pp. 259-275. https://doi.org/10.1080/02607476.2010.497366

44. Smith, R.; Stockley, D.; Ahmad, A.; Hastings, A.; Kinderman, L. and Gauthier, L. (2017). "Perspectives on the impact of the 3M national teaching fellowship program", Innovations in Education and Teaching International, Vol. 54, No. 4, pp. 386-393. https://doi.org/10.1080/14703297.2016.1255154

45. Williamson, M. (2011), "Inside out: turning consumers back into students", Three D Issue 17, UK: Media, Communication and Cultural Studies Association. Available from: http://www.meccsa.org.uk/news/three-d-issue-17-inside-outturning-consumers-back-into-students/ [Accessed 1 June 2015].

46. Yin, R. (2011), Qualitative Research from start to Finish, London: The Guildford Press.

International Journal of Management and Applied Research, 2020, Vol. 7, No. 4 